\title{
NIH Grant Funding: Why Should it Change and How
}

\section{Mihai D Niculescu*}

UNC Nutrition Research Institute and Department of Nutrition, UNC Gillings School of Public Health, University of North Carolina at Chapel Hill, Kannapolis, NC, USA

I admit that I had to take a deep breath before starting to write this editorial. When I received the JNDT's invitation to write it, my first thought was "what would be the best and hot subject in my field? Nutrition, epigenetics, metabolomics?" Then, almost painfully, I realized (again) that, for many of us who dedicate most of our life time to science here in US (but not only), the hottest subject is, oddly enough, not THE SCIENCE. It is rather the MEANS we need to do science. Meaning FUNDING. So I decided that talking about NIH funding is a great topic, albeit extremely controversial. But I do this not only to point out to the mechanisms that, in my opinion, are plainly broken, but also to propose an alternative to a system that became frustrating, discouraging, and maybe partially obsolete for an increasing legion of scientists (both junior and senior).

\section{The Problem and its Origins}

To simply put it, the problem is that less and less money is available for research, compounded by an increasing number of researchers who apply for funding. According to FASEB report "PREDICTABLE AND SUSTAINABLE FUNDING FOR NIH WILL DRIVE INNOVATION AND PROGRESS", the decrease in funding (constant dollars) began in 2003, while the number of research project grants funded has declined continuously since 2004 [1]. As a consequence, the success rate is at its lowest (around 18\%) since 1993 (the first year included in this report). Today almost anyone knows of a colleague who had to diminish its laboratory staff or who, even worse, had to go because of sudden lack of funding. Even well-established investigators are affected by this trend. But the direst situation is for the junior faculty, those who are struggling to obtain NIH funding for the first time.

The origins of the NIH funding process problems are new only in part, and they have become obvious recently only because the funding situation has become so acutely dramatic, that now we have started to really look at the funding process in its entirety.

\section{The Review Process}

I surmise that the review process is partially defective, and this is not a new feature, but rather an old issue that only today has started to receive more scrutiny. I will briefly mention just several factors that cast doubt against the objectivity of the review process. Review accuracy and objectivity are weak, with reviewers not being able to reliably distinguish between a $20^{\text {th }}$ percentile grant from a $5^{\text {th }}$ percentile grant [2]. Today, when new grants funded are getting close to the $5-8^{\text {th }}$ percentiles, this inability to differentiate has become a major problem. Secondly, how many of us recognize the following situation? After the application has received a score, one works hard to improving it according to the reviewers' comments (a.k.a. making it more complete), only to receive a lower score for resubmitted proposal. Not being able to continue a review process on the same coordinates is a strong indicator of bias.

A third issue is, I think, as serious as the first two. It is about the expertise of some reviewers. Do not get me wrong! I want that junior investigators to be better involved in the strategic decisions that would improve the scientific environment in U.S. However, the last thing one wishes is the lack of proven expertise when it comes to reviewing applications. Problem is that, among the reviewers invited by NIH (for both primary reviews and review panels), one can find very often reviewers who did not receive (yet) NIH funding (read R01). There is a logical quandary here. What are one's credentials that make him or her fit for reviewing an R01, if the reviewer could not get one yet? What is the impact of having new investigators review proposals for a category of grants for which they did not prove themselves?

\section{The marketing}

"The truth is in the eye of the beholder" should not be an adage that governs any scientific endeavor. Yet and too often, much of the success of a grant proposal lays not necessarily in the scientific quality of the proposed work, but rather in the applicant's ability to convince us that the proposal is fit for funding. In other words, we demand the scientist to be a good marketer for a product that does not yet exist, but we only get the promise of its inception in the future. Why is this wrong? Because people have different abilities in convincing others. Some of us know very well how to "sell" their ideas, while others have problems with this. But, in the end, it does not mean that the best "sellers" are the best scientists, nor vice versa. It is all in the image rather than in the substance.

\section{The Consequences}

I believe that everyone feels that the time we put in trying to get funded could be used much better. Most of us spend more than $50 \%$ of their time writing proposals, with a chance of getting funded below the $10^{\text {th }}$ percentile (and descending quickly towards the $5^{\text {th }}$ ). That means that, in average, we spend $90 \%$ of the time dedicated to proposals for nothing, knowing very well that only maybe $10 \%$ of our effort will translate into successful funding. I say on average, because many are spending their time on proposals that are never funded. The rest of the time we spend on writing papers and teaching. But we have to ask ourselves: how much success in science can one have when hardly spends time in the lab? How much peace of mind can one have when, everyday, one thinks about how to support his or her people in the lab, and how to get more funds to continue the research? How much time one has to keep up with the logarithmic increase of new information in the field?

This is not sustainable, and more of us are feeling the pinch, then the pain, of continuously and almost totally spending the time on...writing proposals. I remember, years ago, being a kid who, in his naiveté, was imagining that science means to stare for hours through the lenses of a microscope, to spend the nights in the lab in front of glass tubes, and so on. But what was I thinking? After all, those were the dreams of a silly kid.

*Corresponding author: Mihai D Niculescu, Rm. 2014, 500 Laureate Way, Kannapolis, NC 28027, USA, Tel: +1 (704) 250 5029; Fax: +1 (704) 2505001 E-mail: Mihai_Niculescu@unc.edu

Received November 08, 2012; Accepted November 09, 2012; Published November 12, 2012

Citation: Niculescu MD (2013) NIH Grant Funding: Why Should it Change and How. J Nutr Disorders Ther 3:e104. doi:10.4172/2161-0509.1000e104

Copyright: $\odot 2013$ Niculescu MD. This is an open-access article distributed under the terms of the Creative Commons Attribution License, which permits unrestricted use, distribution, and reproduction in any medium, provided the original author and source are credited. 


\section{Oh...wait, I have an idea}

Imagine this scenario, which I propose only for the investigatorinitiated science (including the renewal of investigator-initiated projects). Considering the funds available today, NIH sets a cap in the number of investigators to receive funding (let us say the same number of investigators that today NIH funds using the program announcement (PA) mechanism). For the sake of the argument, let us put this number to 10,000 principal investigators (PI). In order to initiate the new mechanism, NIH will continue to fund each PI at the 2012 level for a 5 -year cycle. At the end of the cycle, a review process will include one report prepared by the PI (let us say provided 6 months in advance). This report should reflect the PI's scientific achievements during the 4.5 years of activity. A review panel (or more) will review and score these achievements. Those who are in a junior position and have not yet received funding (let us say another 1,000 PIs), will also prepare a report and submit it to NIH. In the end, 11,000 PIs will be scored for the significance, impact, innovation, and quality of their research during the past cycle. NIH will fund only the established number of PIs $(10,000)$ according to their score, by dividing the available funds accordingly, as the fund distribution will be related to the score.

\section{The Advantages}

I see many advantages in such a system, and only one disadvantage (which I will also mention). Here are few:

- The investigators will dedicate most of their time to science, instead of writing proposals with minimal chances of success;
- The NIH budget dedicated to the review process will decrease sharply, as the review panels will have to review a lot fewer reports than today's number of applications;

- The merit for funding will be centered around actual scientific work, rather than around promises;

- The elimination of pilot data generation will allow more continuity in developing scientific ideas that have been already funded in a previous cycle (if funding continues);

- Pioneering research will be assessed "as is", while today few projects with high risk/high yield ratio are funded. This will allow a steeper progress in discovery.

One disadvantage is that some researchers will not be funded anymore during the next cycle. But, truly, is it not the same thing happening today? However, they can still be supported by their own department, and be given the chance to obtain funding at next cycle.

This is just a sketch of an alternative funding mechanism, and much tweaking would be needed to make it viable. But maybe the time has come to say farewell to a system that has lived its life, and which does not respond to the new reality of what it takes for science to go further successfully.

\section{References}

1. http://www.faseb.org/LinkClick.aspx?fileticket=aDQINW4adp0\%3D\&tabid $=431$

2. Wadman M (2011) NIH firm on grant application rules. Nature 471: 558. 